close proximity to the origin of the inferior mesenteric artery. Animal studies have shown laminar flow in the aorta and toxic damage to the mucosa after infusion of hyperosmolar solutions. ${ }^{3}$

Accurate placement in relation to the aortic bifurcation may be achieved with ultrasound imaging. This dispenses with the need for a confirmatory radiograph, reducing the total radiation to the infant. Failure to visualise the catheter in the iliac artery will indicate that it has been inadvertently placed in the umbilical vein or outside the arterial system. From our experience with an infant in whom thrombosis associated with an intra-arterial catheter was recognised, we believe that regular ultrasonic examination should help in the assessment of this complication.

With the established value of real time ultrasound scanning in neonatology and the increasing availability of the equipment, this technique is now feasible in most neonatal units. We therefore recommend that an umbilical arterial catheter should be inserted under ultrasound screening and the tip placed 5-10 $\mathrm{mm}$ above the aortic bifurcation. A confirmatory radiograph is not required.

\section{References}

1 Cockburn F, Drillen CM. Neonatal medicine. Oxford: Blackwell Scientific Publications, 1974.

2 Phelps DL, Lachman RS, Leake RD, Oh W. The radiologic localization of the major aortic tributaries in the newborn infant. J Pediatr 1972;81:336-9.

3 Book LS, Herbst JJ. Intra-arterial infusions and intestinal necrosis in the rabbit: potential hazards of umbilical artery injections of ampicillin, glucose, and sodium bicarbonate. Pediatrics 1980;65:1145-9.

Correspondence to Dr A B Houston, Department of Neonata Paediatrics, Royal Maternity Hospital, Glasgow G4.

Received 30 August 1983

\title{
Fatal, low renin hypertension associated with a disturbance of cortisol metabolism
}

\author{
J W HONOUR, M J DILLON, M LEVIN, AND V SHAH \\ Division of Clinical Chemistry, MRC Clinical Research Centre, Harrow, and Hospital for \\ Sick Children, Great Ormond Street, London
}

SUMMARY A 5 month old boy died after fever, persistently raised blood pressure, and hypokalaemia. A disorder of cortisol metabolism caused by $11 \beta$ hydroxysteroid dehydrogenase deficiency was detected retrospectively.

Hypertension associated with renal potassium wasting and alkalosis in children is usually renin dependent, with secondary hyperaldosteronism. When renin and aldosterone production are suppressed this type of clinical presentation may occur where there is (a) increased adrenal production or mineralocorticoid hormones are being given; (b) ingestion of compounds with mineralocorticoid activity, such as liquorice; or (c) a disorder of electrolyte homeostasis, such as Liddle's syndrome. ${ }^{1}$ The latter is a rare, familial cause of hypertension ascribed to a generalised disorder of ion transport ${ }^{2}$ in which the raised blood pressure and electrolyte disturbance may be corrected by triamterine. In other similar disorders a mineralocorticoid excess state may be suggested by a favourable clinical response to the mineralocorticoid antagonist, spironolactone. ${ }^{3}$ Specific investigation of children with this disorder has shown subnormal production of identifiable mineralocorticoid hormones and cortisol partly caused by a defect of the $11 \beta$-hydroxysteroid dehydrogenase, which is normally responsible for peripheral equilibration of cortisol with the less active cortisone. ${ }^{4}$ We report a 5 month old boy who seems to be the youngest child identified with $11 \beta$-hydroxysteroid dehydrogenase deficiency, and the first fatal case.

\section{Case report}

A boy, the second child of healthy, unrelated parents was delivered by caesarean section at 37 weeks' gestation because of poor fetal growth. Birthweight was $2 \cdot 36 \mathrm{~kg}$ and the placenta was small and infarcted. Apgar scores were 6 at 1 minute and 9 at 5 minutes. In the neonatal period he had prolonged hyperbilirubinaemia, for which no cause was found. The maximum bilirubin was $230 \mu \mathrm{mol} / 1$ $(13.4 \mathrm{mg} / 100 \mathrm{ml})$ on day 5 of life. This seemed to settle spontaneously but at age 1 month the child was investigated again because mild jaundice persisted. 
During the course of these investigations a sudden episode of apnoea followed by lethargy and irritability occurred. A computed tomogram showed no clear evidence of an intracranial haemorrhage, but a lumbar puncture showed xanthochromic cerebrospinal fluid and it was believed that a small subarachnoid haemorrhage had occurred. His blood pressure was not recorded but plasma electrolytes and liver function tests were normal and no evidence of infection was found.

At age 5 months, after a 24 hour history of diarrhoea and vomiting he was admitted to hospital because of fever and persistently raised blood pressures (maximum $200 / 100 \mathrm{~mm} \mathrm{Hg}$ ). He was a well hydrated, vigorous baby with no physical abnormalities. He was found to be consistently hypokalaemic (plasma potassium $1.8 \mathrm{mmol} / \mathrm{l}$ ) and alkalotic (plasma $\mathrm{TCO}_{2} 29 \mathrm{mmol} / \mathrm{l}$ ) but renal and liver function were essentially normal. A chest radiograph showed mild cardiomegaly but an electrocardiograph and an abdominal ultrasound were normal.

Treatment with parenteral labetolol and subsequently oral hydrallazine and propranolol was only partially effective. His blood pressure fluctuated considerably, and three days after admission his condition deteriorated with acute cardiac decompensation followed by arrest. In spite of resuscitative efforts he died $5 \frac{1}{2}$ hours later. Although a necropsy was refused, cytomegalovirus (CMV) infection was confirmed after death. This was thought to have been recently contracted since the CMV complement fixing titre in the neonatal period was low. Specific investigative results became available after death and showed very low plasma renin activity and plasma aldosterone concentration. Vanillylmandelic acid excretion in urine, examined by using a gas chromatographic screening procedure, was considered to be within normal limits, but plasma noradrenaline concentration was moderately raised (Table). Analysis of steroids in the urine using gas

Table Results of specific tests

\begin{tabular}{|c|c|c|c|}
\hline & \multirow[t]{2}{*}{ Patient } & \multicolumn{2}{|c|}{$\begin{array}{l}\text { Age matched } \\
\text { controls }\end{array}$} \\
\hline & & Range & (No) \\
\hline $\begin{array}{l}\text { Plasma renin activity (ng } \mathrm{Al} / \mathrm{l} / \mathrm{h}) \\
\text { Plasma aldosterone }(\mathrm{pmol} / \mathrm{l}) \\
\text { Plasma noradrenaline }(\mathrm{pg} / \mathrm{ml}) \\
\text { Urinary vanillylmandelic acid }\end{array}$ & $\begin{array}{l}20 \\
30 \\
1600 \\
\text { Normal }\end{array}$ & $\begin{array}{l}470-3130 \\
160-2390 \\
110-670\end{array}$ & $\begin{array}{l}(18) \\
(18) \\
(6)\end{array}$ \\
\hline $\begin{array}{l}\text { Urinary steroid excretions } \\
\text { Tetrahydrocortisone }(\mu \mathrm{mol} / 24 \mathrm{~h}) \\
5 \alpha \text {-tetrahydrocorticosterone } \\
(\mu \mathrm{mol} / 24 \mathrm{~h}) \\
\text { Tetrahydrocortisol }(\mu \mathrm{mol} / 24 \mathrm{~h}) \\
5 \alpha \text {-tetrahydrocortisol }(\mu \mathrm{mol} / 24 \mathrm{~h}) \\
\text { Total cortisol metabolites } \\
(\mu \mathrm{mol} / 24 \mathrm{~h})\end{array}$ & $\begin{array}{l}17 \\
140 \\
80 \\
1090 \\
1200\end{array}$ & $\begin{array}{l}1150-1700 \\
130-520 \\
340-1190 \\
330-500 \\
2030-3850\end{array}$ & $\begin{array}{l}\text { (3) } \\
\text { (3) } \\
(3) \\
\text { (3) } \\
\text { (3) }\end{array}$ \\
\hline
\end{tabular}

chromatography with a capillary column ${ }^{4}$ did not confirm excess secretion of any mineralocorticoid hormone or cortisol precursor. The pattern was, however, consistent with $11 \beta$-hydroxysteroid dehydrogenase deficiency-the excretion rate of metabolites of cortisone being low and those of cortisol high. Total steroid excretion was low when compared with normal age matched boys (Table).

\section{Discussion}

This is the youngest child known to have $11 \beta$-hydroxysteroid dehydrogenase deficiency and, as far as we are aware, the first fatal case. The preterminal gastroenteric presentation may have been related to an acute CMV infection but this cannot account for the course of events. At least one previously reported child had similar crises-the 3 year old infant described by New et al. ${ }^{3}$ had several hospital admissions for gastroenteritis and recovered without specific treatment. In older infants with this disorder, however, failure to thrive is a commoner presentation. ${ }^{4}$

From extensive investigations, often over several years, ${ }^{6} 11 \beta$-hydroxysteroid dehydrogenase deficiency seems to be a sodium dependent, adrenocorticotrophic hormone exacerbated, hypertensive disorder associated with hypokalaemia. Blood pressure may or may not be low, even when adrenal steroid secretion is suppressed after giving dexamethasone or when electrolyte status is changed by either dietary manipulation of electrolyte intake or pharmacological modification of renal excretion. The improvement with spironolactone suggests that mineralocorticoid hormones $(\mathrm{MCH})$ are involved but in some cases this $\mathrm{MCH}$ antagonist is ineffective and blood pressure can only be lowered to normal by giving triamterine. ${ }^{45}$ Measurements of mineralocorticoid activity have yielded conflicting results and it is suggested that as an alternative to mineralocorticoid excess, these children may have a generalised disorder of sodium and potassium transport in which the distal renal tubules seem particularly responsive to very small amounts of mineralocorticoid. In this disorder, cortisol may act as a more potent mineralocorticoid than in normal individuals. $^{6}$

This case emphasises the need to include blood pressure measurements in routine examination of sick infants and children. Hypertension in this child might have been identified earlier and indeed could have been the cause of the subarachnoid haemorrhage at age 6 weeks. It also stresses the need to consider $11 \beta$-hydroxysteroid dehydrogenase deficiency in hypertensive children with notable hypokalaemia. Although the commonest cause of this is secondary 
hyperaldosteronism caused by a renin dependent hy pertensive state, appropriate treatment would be very different, with the need to consider spironolactone or triamterine (as might have been helpful in our patient), before the diagnosis is established.

This work was supported in part by a grant from the Kidney Research Aid Fund. We are grateful to Dr P Sever, St Mary's Hospital, London, for measurement of plasma noradrenaline.

\section{References}

1 Liddle GW, Bledsoe T, Coppage WS. A familial renal disorder simulating primary aldosteronism but with negligible aldosterone secretion. In: Baulieu EE, Robel P, eds. Aldosterone. Oxford: Blackwell Scientific, 1964: 353-68.

2 Gardner JD, Lapey A, Simopoulos AP, Bravo EL. Abnormal membrane sodium transport in Liddle's syndrome. J Clin Invest $1971 ; 50: 2253-8$.

3 New MI, Levine LS, Biglieri EG, Pareira J, Ulick S.
Evidence for an unidentified steroid in a child with apparent mineralocorticoid hypertension. $J$ Clin Endocrinol Metab 1977;44:924-33.

4 Shackleton CHL, Honour JW, Dillon MJ, Chantler C, Jones RWA. Hypertension in a four year old child: gas chromatographic and mass spectrometric evidence for deficient hepatic metabolism of cortisol. J Clin Endocrinol Metab 1980;50:786-92.

5 Fiselier TJW, Otten BJ, Monnens LAH, Honour JW, Van Munster PJJ. Low renin, low-aldosterone hypertension and abnormal cortisol metabolism in a 19 month old child. Horm Res 1982;16:107-14.

6 Oberfield SF, Levine LS, Carey RM, Greig F, Ulick S, New MI. Metabolism and blood pressure responses to hydrocortisone in the syndrome of apparent mineralocorticoid excess. J Clin Endocrinol Metab 1983;56:332-9.

Correspondence to Dr J W Honour, Cobbold Laboratories, Thorn Institute of Clinical Science, The Middlesex Hospital Medical School, London WIN 8AA.

Received 25 July 1983

\title{
Early treatment of familial hypophosphataemic rickets
}

\author{
M ROZA, M A MIGUEL, M GALBE, L MEJIDO, AND C MENCIA \\ Department of Paediatrics, Hospital General de Asturias, Oviedo, Spain
}

SUMMARY A $2 \frac{1}{2}$ year old girl in whom familial hypophosphataemic rickets was diagnosed at age 2 months, has been treated since then with oral $1 \alpha, 25$-dihydroxycholecalciferol and phosphate. She has not, so far, developed osseous lesions.

Recent research into the metabolism of vitamin D has led to knowledge of its active forms and treatment applications. Despite its successful therapeutic effects in hypophosphataemic rickets (HR), opening a new field in the physiopathological research into this disease, not all the mechanisms are known. We present a patient in whom the early treatment of familial HR with 1 $\alpha, 25$-dihydroxycholecalciferol $\left(1 \propto, 25\left(\mathrm{OH}_{2}\right)_{3}\right)$ and phosphate (Joulie's solution) prevented the onset of bone lesions.

\section{Case report}

A girl, aged $2 \frac{1}{2}$ years at the time of this report, had been observed since birth. Her mother was known to have a sporadic form of HR with severe bone abnormalities (osteomalacia) and dwarfism, and had been treated during infancy with combined phosphates and vitamin $\mathrm{D}_{3}$ without any improvement. The pregnancy was normal, and a caesarean section was performed for maternal indications.
Our patient's birthweight was $3.3 \mathrm{~kg}$ and her length was $52 \mathrm{~cm}$.

A physical examination at age 2 months showed her to be normal-weight and height at the 25 th centile. Laboratory investigations at that time found the following: hypophosphataemia-phosphate 113 $\mathrm{mmol} / \mathrm{l}(3 \cdot 5 \mathrm{mg} / \mathrm{dl})$, normal range for our laboratory $1 \cdot 29-2 \cdot 09 \mathrm{mmol} / \mathrm{l}$; normal serum calcium-2.3 $\mathrm{mmol} / \mathrm{l}(9 \cdot 2 \mathrm{mg} / \mathrm{dl})$, normal range $2 \cdot 1-2 \cdot 6 \mathrm{mmol} / \mathrm{l}$; raised alkaline phosphatase - $56 \mathrm{KA}$ units, normal range $7 \cdot 5-32.5 \mathrm{KA}$ units; hypocalciuria-0.0365 $\mathrm{mmol} / \mathrm{kg} / 24$ hours $(1.46 \mathrm{mg} / \mathrm{kg} / 24$ hours $)$; hyperphosphaturia- $45.54 \mathrm{mmol} / 1 \cdot 73 \mathrm{~m}^{2} / 24$ hours $(1.41$ $\mathrm{mg} / 1 \cdot 73 \mathrm{~m}^{2} / 24$ hours); and a reduction in renal tubular reabsorption of phosphate $-60 \%$.

Renal function parameters were normal: glomerular filtration rate (GFR) estimated by creatinine clearance was $70 \mathrm{ml} / 1 \cdot 73 \mathrm{~m}^{2} /$ minute, with GFR of sodium, calcium, and potassium 0.09 $\mathrm{ml} / 100 \mathrm{ml}, 0.17 \mathrm{ml} / 100 \mathrm{ml}$, and $6.98 \mathrm{ml} / 100 \mathrm{ml}$ of filtrate. Aminoaciduria was normal, urine density was 1028; and $\mathrm{pH}$ 5. Plasma bicarbonate was $23 \cdot 8$ (mEq) $\mathrm{mmol} / \mathrm{l}$ and plasma $\mathrm{pH}$ was $7 \cdot 38$. After intravenous loading of phosphate there was an important reduction in the maximal tubular excretory capacity of phosphate (GFR $3.6 \mathrm{mg}(1.2 \mathrm{mmol}) /$ $100 \mathrm{ml}$ filtrate). Knee and wrist radiographs were normal. 